\title{
Self-assembled Monolayer Enables Hole Transport Layer-Free Organic Solar Cells with 18\% Efficiency and Improved Operational Stability
}

Yuanbao Lin, ${ }^{\dagger}$ Yuliar Firdaus, ${ }^{\dagger}, *$ Furkan H. Isikgor, ${ }^{\dagger}$ Mohamad Insan Nugraha, ${ }^{\dagger}$

Emre Yengel, ${ }^{\dagger}$ George T. Harrison, ${ }^{\dagger}$ Rawad Hallani, ${ }^{\dagger}$ Abdulrahman El-Labban, ${ }^{\dagger}$ Hendrik Faber, ${ }^{\dagger}$ Chun Ma, ${ }^{\dagger}$ Xiaopeng Zheng, ${ }^{\S}$ Anand Subbiah, ${ }^{\dagger}$ Calvyn T. Howells, ${ }^{\dagger}$ Osman M. Bakr, ${ }^{\S}$ Iain McCulloch, ${ }^{\dagger}$ Stefaan De Wolf, ${ }^{\dagger}$ Leonidas Tsetseris, ${ }^{\star}$ Thomas D. Anthopoulos $^{\dagger}, *$

${ }^{\dagger}$ King Abdullah University of Science and Technology (KAUST), KAUST Solar Center (KSC), Thuwal 23955, Saudi Arabia

${ }^{\S}$ King Abdullah University of Science and Technology (KAUST), Physical Science and Engineering Division (PSE), Thuwal 23955, Saudi Arabia.

$\star$ Department of Physics, National Technical University of Athens, Athens GR-15780, Greece

AUTHOR INFORMATION

\section{Corresponding Authors}


*Email: thomas.anthopoulos@kaust.edu.sa; yuliar.firdaus@kaust.edu.sa

\section{Experimental details}

Solar Cell Fabrication: 2PCAz was purchased from Tokyo Chemical Industry (TCI) Co., LTD. N3 was purchased from eFlexPV Inc. PFN-Br, PM6, and BTP-eC9 were purchased from Solarmer Materials Inc. Indium tin oxide (ITO) coated glass substrates (Kintec Company, $10 \Omega$ sq. $^{-1}$ ) were cleaned by sequential ultrasonication in dilute Extran 300 detergent solution, deionized water, acetone, and isopropyl alcohol for 10 min each. The substrates were then subjected to a UV-ozone treatment step for 10 min. Next, a thin layer $(\approx 40 \mathrm{~nm})$ of PEDOT:PSS was spin-coated onto the UV-treated substrates and then dried on a heating plate at $150{ }^{\circ} \mathrm{C}$ for $10 \mathrm{~min}$. For $2 \mathrm{PCAz}$ devices, the $2 \mathrm{PCAz}\left(1 \mathrm{mg} \mathrm{mL}^{-1}\right.$ in ethanol) was spin-coated at $8000 \mathrm{rpm}$ onto 10 minutes plasma-treated substrates outside, and then dried on a heating plate at $150{ }^{\circ} \mathrm{C}$ for 25 min. The samples were then transferred into a dry nitrogen glove box $\left(<10 \mathrm{ppm} \mathrm{O}_{2}\right)$. PM6:N3 (ratio 1:1.2, $16 \mathrm{mg} \mathrm{mL}^{-1}$ in chloroform and added 0.5 vol\% chloronaphthalene) were then spun at $3200 \mathrm{rpm}$ for $30 \mathrm{~s}$ to obtain an active-layer thickness around $110 \mathrm{~nm}$. PM6:BTP-eC9:PC ${ }_{71} \mathrm{BM}$ (ratio 1:1:0.2, $17 \mathrm{mg} \mathrm{mL}^{-1}$ in chloroform and added $0.5 \mathrm{vol} \% \mathrm{DIO}$ ) were then spun to obtain an active-layer thickness around $100 \mathrm{~nm}$. The active layer was annealed at $100{ }^{\circ} \mathrm{C}$ for $10 \mathrm{~min}$. A layer of $5 \mathrm{~nm}$ of PFN-Br $\left(0.5 \mathrm{mg} \mathrm{mL}^{-1}\right.$ in methanol) was spun from on top of the BHJ layer. Finally, the samples were placed in a thermal evaporator and $100 \mathrm{~nm}$ of silver was then thermally evaporated at $5 \times 10^{-6}$ mbar through a $0.1 \mathrm{~cm}^{2}$ pixel area shadow mask.

Density Functional Theory (DFT) calculations: The results on the structures, HOMO, 
and LUMO for PM6 (modelled as a dimer) and N3 were obtained with the DFT code NWChem $^{1}$, the B3LYP exchange-correlation (xc) functional ${ }^{2-3}$ and the DZVP orbital basis $^{4}$. All results on ITO were obtained with the DFT code Quantum Espresso ${ }^{5}$, an energy cutoff of 75 Rydbergs for the plane-wave basis, projector augmented waves ${ }^{6}$, and the generalized gradient approximation Perdew-Wang xc functional ${ }^{7}$. Structures were rendered with the software VESTA ${ }^{8}$. To model the (111) ITO surface we used slabs with three or four layers of the material in its cubic bixbyite crystal structure. The results we report in the main text are based on the four-layer case and correspond to large supercells with stoichiometry $\operatorname{In}_{60} \mathrm{Sn}_{4} \mathrm{O}_{96}$. To describe various $2 \mathrm{PACz}$ chemisorption configurations we considered a large number of cases with single, double, or triple covalent anchoring to the surface and with the acidic hydrogen atoms attached to ITO O sites either as individual species or in pairs (i.e. forming adsorbed water molecules).

Optical Simulation: Simulations of normalized electric-field intensity $\left(|\mathrm{E}|^{2}\right)$, parasitic absorption, and exciton generation of the OPV devices were calculated by transfermatrix optical modelling. ${ }^{9}$ This method calculates the reflection and transmission at each interface and the interference between the incident electric field and the fields reflected from the Ag back electrode as well as attenuation in each layer. The optical constants (refractive index, extinction coefficient) for the active layer were collected by variable angle spectroscopic ellipsometry (VASE).

Device Characterization: UV-vis spectra were recorded on a Cary 5000 instrument in single beam mode in $1 \mathrm{~cm}$ quartz cuvettes. $J-V$ measurements of solar cells were 
performed in an $\mathrm{N}_{2}$ filled glove box using a Keithley 2400 source meter and an Oriel Sol3A Class AAA solar simulator calibrated to 1 sun, AM1.5G, with a KG-5 silicon reference cell certified by Newport. External quantum efficiency (EQE) was characterized using an EQE system (PV measurement Inc.). Measurements were performed at zero bias by illuminating the device with monochromatic light supplied from a Xenon arc lamp in combination with a dual-grating monochromator. The number of photons incident on the sample was calculated for each wavelength by using a silicon photodiode calibrated by The National Institute of Standards and Technology (NIST). The internal quantum efficiency (IQE) of OSC was calculated from Equation: $\operatorname{IQE}(\%)=\mathrm{EQE}(\%) /(100 \%-$ Reflectance $(\%)-$ Parasitic Absorption (\%). Bruker atomic force microscope (AFM) was used to image the surface of the various layers in tapping mode. Scanning electron microscopy (SEM) measurements were performed using a Zeiss Auriga microscope equipped with in-lens detector. Operational stability test was performed using Lakeshore CRX-4K cryogenic probe station where the samples are illuminated with white light (Thorlabs, MCWHL5) in high vacuum environment. During the stability test, perturb and observe algorithm is performed for the maximum power point tracking.

X-ray photoelectron spectroscopy: X-ray photoelectron spectroscopy was carried out using an (Omicron) multi-probe ultrahigh vacuum (UHV) chamber operated at $10^{-10}$ mbar and equipped with a monochromated AlK $\alpha(1486.6 \mathrm{eV}) \mathrm{X}$-ray source $(15 \mathrm{kV}, 26$ $\mathrm{mA}$ ) and a hemispherical EAC125 Sphera 2 analyser with a channeltron detector. Spectra were recorded at a source-analyser angle of $80^{\circ}$, in electrical contact to the 
analyser at sample-analyser angles of $0-75^{\circ}\left(0^{\circ}\right.$ normal to sample plane) without charge neutralisation. The spectra were recorded at a constant pass energy which was $50 \mathrm{eV}$ for survey scans and $15 \mathrm{eV}$ for high resolution scans. Binding energy calibration was made using a $\mathrm{Ar}^{+}$sputter cleaned evaporated $\mathrm{Au}$ film, calibrating to the $\mathrm{Au} 4 \mathrm{f} 7 / 2$ peak at $84 \mathrm{eV}$. Samples were transferred directly to UHV with a minimal time of ambient exposure and measured without further preparation. CasaXPS software was used for all peak fitting and analysis with mixed Gaussian/Lorenztian peaks (30/70) and Shirley background.

Light-Intensity Dependence Measurements: Light-intensity dependence measurements were performed with PAIOS instrumentation (Fluxim) (steady-state and transient modes). Transient photo-voltage (TPV) measurements monitor the photovoltage decay upon a small optical perturbation during various constant light-intensity biases and at open-circuit bias conditions. Variable light-intensity biases lead to a range of measured $V_{\mathrm{OC}}$ values that were used for the analysis. During the measurements a small optical perturbation $\left(<3 \%\right.$ of the $V_{\mathrm{OC}}$, so that $\left.\Delta V_{\mathrm{OC}}<<V_{\mathrm{OC}}\right)$ is applied. The subsequent voltage decay is then recorded to directly monitor bimolecular charge carrier recombination. The photovoltage decay kinetics of all devices follow a mono-exponential decay: $\delta V=$ A $\exp (-t / \tau)$, where $t$ is the time and $\tau$ is the charge carrier lifetime. The "charge extraction" (CE) technique was used to measure the charge carrier density $n$ under open-circuit voltage condition. The device is illuminated and kept in open-circuit mode. After light turn-off, the voltage is switched to zero or taken to short-circuit condition to extract the charges. To obtain the number of extracted charges, the current is integrated. 
The carrier lifetimes follow a power law relationship with charge density: $\tau=\tau_{0} n^{-\lambda}$. The bimolecular recombination constant $k_{\text {rec }}$ were then inferred from the carrier lifetimes and densities according to $k_{\mathrm{rec}}=1 /(\lambda+1) / n \tau^{2}$, where $\lambda$ is the recombination order. TPC analyses measure the time-dependent extraction of photogenerated charge carriers. During the measurement, the device is set under short-circuit condition; a $200 \mu$ s light pulse is used allowing the current density to reach the steady-state condition. PhotoCELIV measurements (ramp rate $200 \mathrm{~V} \mathrm{~ms}^{-1}$, delay time: $0 \mathrm{~s}$, offset voltage: $0 \mathrm{~V}$, lightpulse length: $100 \mu \mathrm{s}$ ) were also performed using PAIOS for different light intensities. The light intensity is given in the maximum power of the LED source $(100 \% \approx 200$ $\left.\mathrm{mW} \mathrm{cm} \mathrm{cm}^{-2}\right)$

Electrochemical Impedance Spectroscopy (EIS): EIS was conducted using a commercially available PAIOS. The measurements were performed using conditions that had an applied bias of open circuit voltage of OPV in the dark, and a frequency ranging from $3 \mathrm{MHz}$ to $300 \mathrm{~Hz}$. 
Table S1. Summary of performance parameters of OPVs incorporating different SAMs in their cathode or anode electrodes.

\begin{tabular}{|c|c|c|c|c|c|}
\hline & lectrode system & Structure & BHJ & $\operatorname{PCE}(\%)$ & Ref. \\
\hline \multirow{12}{*}{ P-type } & $2 \mathrm{PACz}$ & ITO-SAM/BHJ/PFN-Br/Ag & \multirow{3}{*}{ PM6:N3 } & 16.6 & \multirow{3}{*}{$\begin{array}{l}\text { This } \\
\text { work }\end{array}$} \\
\hline & PEDOT:PSS & $\begin{array}{c}\text { ITO/PEDOT:PSS/BHJ/PFN- } \\
\mathrm{Br} / \mathrm{Ag}\end{array}$ & & 15.9 & \\
\hline & - & ITO/BHJ/PFN-Br/Ag & & 6.5 & \\
\hline & $2 \mathrm{PACz}$ & ITO-SAM/BHJ/PFN-Br/Ag & PM6:BTP- & 18.0 & This \\
\hline & PEDOT:PSS & $\begin{array}{c}\text { ITO/PEDOT:PSS/BHJ/PFN- } \\
\mathrm{Br} / \mathrm{Ag}\end{array}$ & eC9:PC $\mathrm{PC}_{71} \mathrm{BM}$ & 17.5 & work \\
\hline & $\mathrm{CF}_{3}-\mathrm{SAM}$ & ITO-SAM/BHJ/LiF/Al & \multirow{2}{*}{ P3HT:PC ${ }_{61} \mathrm{BM}$} & 3.2 & \multirow{2}{*}{10} \\
\hline & - & ITO/BHJ/LiF/Al & & 0.8 & \\
\hline & HMDS & ITO-SAM/BHJ/LiF/Al & \multirow{2}{*}{ P3HT:PC ${ }_{61} \mathrm{BM}$} & 1.7 & \multirow{2}{*}{11} \\
\hline & - & ITO/BHJ/LiF/Al & & 1.2 & \\
\hline & $\mathrm{TPDSi}_{2}$ & ITO-SAM/BHJ/LiF/Al & \multirow{3}{*}{$\begin{array}{l}\text { MDMO- } \\
\text { PPV:PCBM }\end{array}$} & 0.9 & \multirow{3}{*}{12} \\
\hline & PEDOT:PSS & ITO/PEDOT:PSS/BHJ/LiF/Al & & 1.3 & \\
\hline & - & $\mathrm{ITO} / \mathrm{BHJ} / \mathrm{LiF} / \mathrm{Al}$ & & 0.8 & \\
\hline \multirow{14}{*}{ N-type } & Serine & ITO-SAM/BHJ/MoO$/ 3 / A 1$ & \multirow{2}{*}{ P3HT:PC ${ }_{61} \mathrm{BM}$} & 4.2 & \multirow{2}{*}{13} \\
\hline & - & $\mathrm{ITO} / \mathrm{BHJ} / \mathrm{MoO}_{3} / \mathrm{Al}$ & & 0.6 & \\
\hline & Zno/MoBA & ITO/ZnO-SAM/BHJ/MoO $/ \mathrm{Ml}_{3}$ & \multirow{2}{*}{ PBDBT:ITIC } & 10.7 & \multirow{2}{*}{14} \\
\hline & $\mathrm{ZnO}$ & $\mathrm{ITO} / \mathrm{ZnO} / \mathrm{BHJ} / \mathrm{MoO}_{3} / \mathrm{Al}$ & & 10.0 & \\
\hline & $\mathrm{ZnO} / \mathrm{C} 60-\mathrm{SAM}$ & ITO/ZnO-SAM/BHJ/MoO $/ \mathrm{Ml}_{3}$ & \multirow{2}{*}{$\begin{array}{c}\text { PTB7:IEICO- } \\
4 \mathrm{~F} \\
\end{array}$} & 10.0 & \multirow{2}{*}{15} \\
\hline & $\mathrm{ZnO}$ & $\mathrm{ITO} / \mathrm{ZnO} / \mathrm{BHJ} / \mathrm{MoO}_{3} / \mathrm{Al}$ & & 9.5 & \\
\hline & $\mathrm{ZnO} / \mathrm{MuA}$ & $\begin{array}{c}\text { ITO/PEDOT:PSS/BHJ/ZnO- } \\
\text { SAM/Al }\end{array}$ & \multirow{2}{*}{ P3HT:PC ${ }_{61} \mathrm{BM}$} & 4.6 & \multirow[t]{2}{*}{16} \\
\hline & $\mathrm{ZnO}$ & ITO/PEDOT:PSS/BHJ/ZnO/Al & & 3.2 & \\
\hline & $\mathrm{ZnO} / \mathrm{BA}-\mathrm{OCH}_{3}$ & $\begin{array}{c}\text { ITO/PEDOT:PSS/BHJ/ZnO- } \\
\text { SAM/Al }\end{array}$ & \multirow[t]{2}{*}{ P3HT:PC ${ }_{61} \mathrm{BM}$} & 4.2 & \multirow[t]{2}{*}{17} \\
\hline & $\mathrm{ZnO}$ & ITO/PEDOT:PSS/BHJ/ZnO/Al & & 3.2 & \\
\hline & $\mathrm{ZnO} / 4$-methylthiazol & $\mathrm{ITO} / \mathrm{ZnOSAM} / \mathrm{BHJ} / \mathrm{MoO}_{3} / \mathrm{Al}$ & \multirow{2}{*}{ P3HT:PC ${ }_{61} \mathrm{BM}$} & 3.6 & \multirow{2}{*}{18} \\
\hline & $\mathrm{ZnO}$ & $\mathrm{ITO} / \mathrm{ZnO} / \mathrm{BHJ} / \mathrm{MoO}_{3} / \mathrm{Al}$ & & 3.1 & \\
\hline & $\mathrm{AZO} / \mathrm{C} 6-\mathrm{C} 60$ & $\begin{array}{c}\text { ITO/ZnO- } \\
\text { SAM/BHJ/PEDOT:PSS/Al }\end{array}$ & \multirow[t]{2}{*}{ P3HT:PC 61 BM } & 3.5 & \multirow[t]{2}{*}{19} \\
\hline & $\mathrm{AZO}$ & ITO/ZnO/BHJ/PEDOT:PSS/Al & & 3.0 & \\
\hline
\end{tabular}




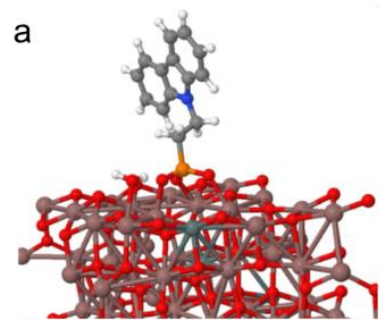

$\mathrm{E}=0.00 \mathrm{eV}$

d

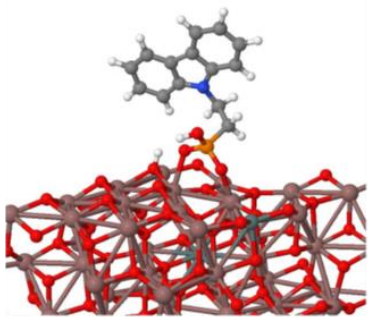

$\mathrm{E}=0.73 \mathrm{eV}$

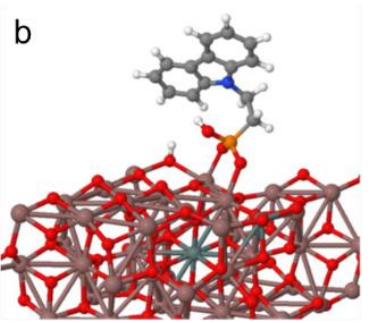

$\mathrm{E}=0.28 \mathrm{eV}$
C

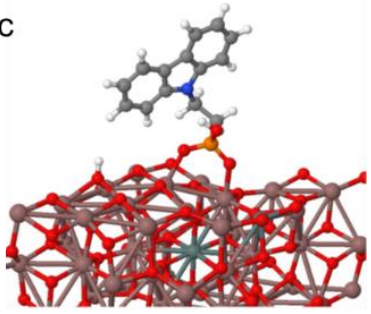

$E=0.50 \mathrm{eV}$

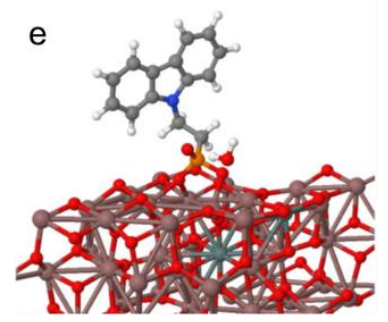

$\mathrm{E}=0.80 \mathrm{eV}$

Figure S1. (a)-(e) Different adsorption configurations for SAMs of 2PACz molecules on the bare (111) surface of ITO. The values give the energy of each structure referenced to the energy of the most stable one (a). For the latter configuration (a), the chemisorption energy with respect to a $2 \mathrm{PACz}$ molecule in a vacuum is about $1.05 \mathrm{eV}$.

\section{S1. XPS analysis for SAM coverage determination}

The SAM coverage on the ITO layer can be quantified and determined from the ratio of the XPS over-layer signal to that of the ITO substrate. Here the integrated intensity of the high-resolution $\mathrm{P}(2 \mathrm{p})$ peak of the $2 \mathrm{PACz}$, and the $\operatorname{In}\left(3 \mathrm{~d}_{5 / 2}\right)$ peak are used, as shown in Figure S2b-c for the photoelectron emission angles $\left(0-75^{\circ}\right)$ used. The method of Paniagua et al. is adapted here. ${ }^{20}$ The XPS ratio expected for an ideal complete or partial monolayer of molecules can first be calculated, requiring some knowledge about the system as outlined here. The relative sensitivity factor (SF) for P ( $2 p)$ and In $\left(3 d_{5 / 2}\right)$ are required, here $\mathrm{SF}(\mathrm{P}) / \mathrm{SF}(\mathrm{In})$ of 0.0895 using the adapted Casa XPS library. Furthermore, these are also modified by a calculated instrumental transmission factor 
$\mathrm{T}(\mathrm{KE})$ specific to the spectrometer and lens apertures $\left(\mathrm{P}(2 \mathrm{p})=6.85, \operatorname{In}\left(3 \mathrm{~d}_{5 / 2}\right)=7.61\right)$. In addition, the emission of photoelectrons from a surface has a finite depth resulting from inelastic and elastic attenuation processes. This can be represented by the attenuation length $\lambda$, which is the thickness at which the intensity reduces to $1 / \mathrm{e}$ at normal angle $0^{\circ}$ and the attenuated intensity is described by the equation Eq. S1 and shown graphically in Figure S2d.

$$
I=I_{0} e^{\left(-\frac{d}{\lambda \cos (\theta)}\right)}
$$

where $\mathrm{I}$ is the attenuated intensity, $\mathrm{I}_{0}$ the non-attenuated intensity, $\mathrm{d}$ the depth from which they originate and $\theta$ the angle with respect to normal.
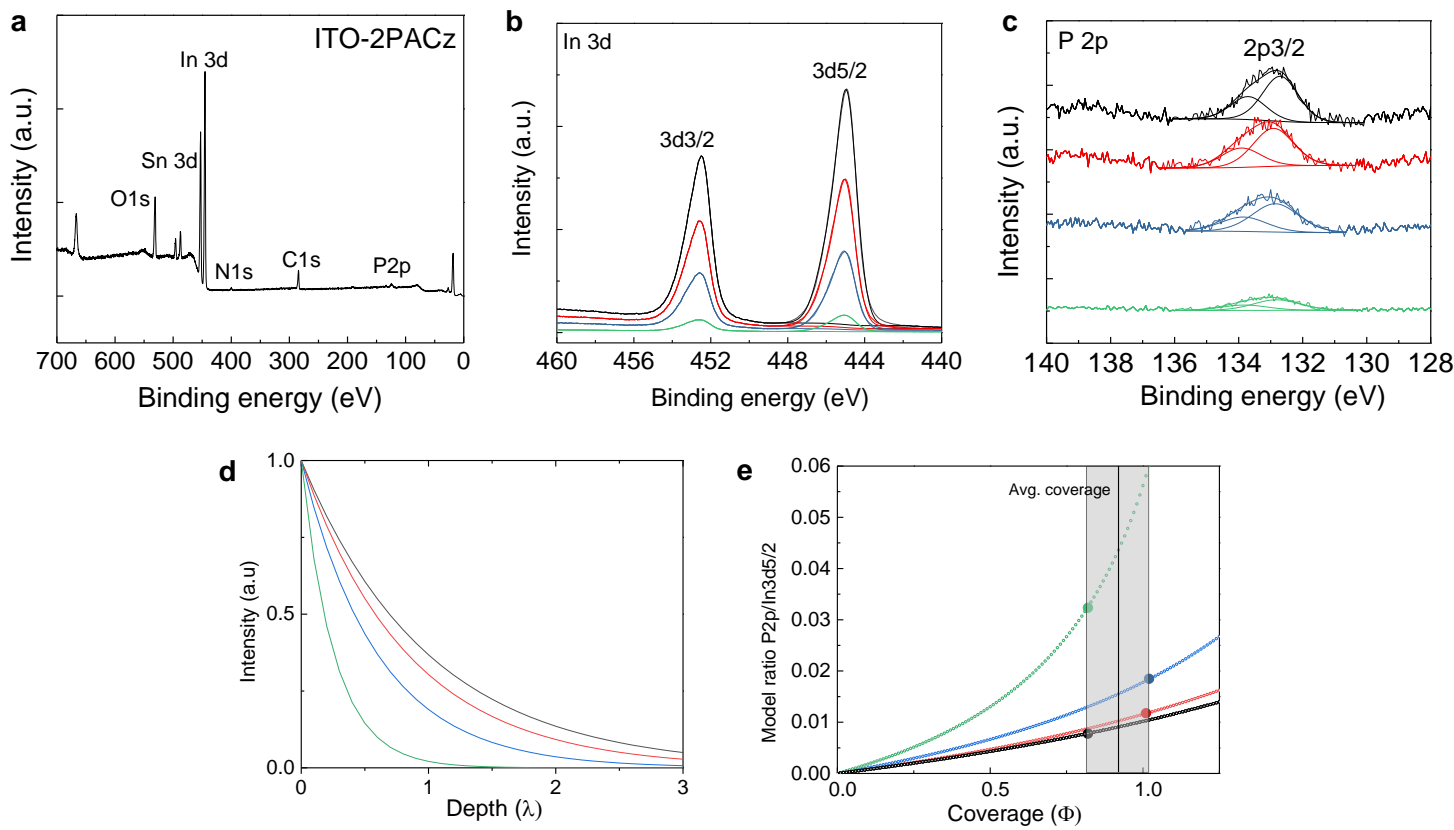

Figure S2. X-ray photoelectron spectroscopy (XPS) of ITO-2PACz from (a) 0-700 eV, (b) $400-460 \mathrm{eV}$, and (c) $128-140 \mathrm{eV}$. (d) Attenuation of intensity as function of depth $\lambda$ in $n m$. (e) The models (Eq. S5) ratio of $\mathrm{P}(2 \mathrm{p}) / \operatorname{In}\left(3 \mathrm{~d}_{5 / 2}\right)$ as a function of coverage. The coloured dots in Figure S2e represent measured data points for each angle and corresponding coverage, read from the $\mathrm{X}$-axis. (The black, red, blue, and green lines in Figure S2b-e mean that emission angle is at $0^{\circ}, 33^{\circ}, 53^{\circ}$, and $75^{\circ}$ ). 
To determine $\lambda$ for ITO the simplified universal attenuation length formula proposed by Seah et al. ${ }^{21}$ is used for ITO and is given as:

$$
\frac{\lambda}{a}=\left(1.861+0.00132 Z^{1.7}+0.0282 E^{0.93}\right) / Z^{0.38}
$$

in monolayers, where $\mathrm{a}$ is the layer thickness in $\mathrm{nm}$ and $\mathrm{Z}$ is the average atomic number $\left(\mathrm{In}_{2} \mathrm{O}_{3}\right)$ and $\mathrm{E}$ is the photoelectron kinetic energy of the core level analysed, here for the In $\left(3 \mathrm{~d}_{5 / 2}\right)$ an $\lambda$ of $2 \mathrm{~nm}$ is calculated.

For the $2 \mathrm{PACz}$ (used later in the calculation), a organic universal formula is chosen: ${ }^{21}$

$$
\lambda=0.00837 E^{0.842}
$$

in $\mathrm{nm}$ for the overlayer $2 \mathrm{PACz} 2.91 \mathrm{~nm}\left(\operatorname{In}\left(3 \mathrm{~d}_{5 / 2}\right)\right)$ and $\mathrm{Cz} 3.61 \mathrm{~nm}(\mathrm{P}(2 \mathrm{p}))$ are used.

If a crystalline surface of ITO is adopted, this presents a surface unit cell containing $28 \mathrm{In}$ atoms and $4 \mathrm{Sn}$ atoms with a layer thickness of $0.332 \mathrm{~nm} .^{22}$ The molecule 2PACz occupies approximately $0.22 \mathrm{~nm}^{2}$ area as used for Phosphonic acid by Paniagua et. al., ${ }^{20}$ which is in close agreement with an earlier QCM (quartz microbalance $)$ study $^{22}$ of $\mathrm{PA}$ on $\mathrm{SiO}_{2} / \mathrm{Si}\left(0.18 \mathrm{~nm}^{2}\right)$ and therefore a full occupancy can be considered to be a maximum of $4.4 \times 10^{14}$ moleculescm $^{-2}$. The ratio of $\mathrm{In}$ in the $n$ underneath layers of each $2 \mathrm{PACz}$ molecule is $(1 / 1.78 n)$. If a depth of $3 \lambda(95 \%$ of intensity) is considered, this leads to a factor of $1 \mathrm{P}$ to $32.16 \mathrm{In}$ atoms for 18.07 layers. To account for attenuation the ratio of the attenuated (area underneath each curve in Figure S2e and non-attenuated intensity is determined and shown in the Table S2 below. Furthermore, the electrons from In and $\mathrm{P}$ are also attenuated by passing through 
the $2 \mathrm{PACz}$ layer (coordinated by the $-\mathrm{PO}_{3} \mathrm{H}$ ), where the height of $2 \mathrm{PACz}$ is effectively $\sim 0.9 \mathrm{~nm}$ for In electrons and $\sim 0.59 \mathrm{~nm}$ for P electrons as inferred from Crystal Maker ${ }^{\circledR}$ software, this correction factor can be expressed in the formula below, reducing to the simple ratio of exponential functions at $1 \mathrm{ML}$ :

$$
\text { Overlayer correction for partial } M L=\frac{\phi e^{\left(-\frac{d C z(0.59 n m)}{\lambda_{P 2 p} \cos (\theta)}\right)}}{1-\phi+\phi e^{\left(-\frac{d 2 P A C z(0.9 n m)}{\lambda_{I} n_{3 d 5 / 2} \cos (\theta)}\right)}}
$$

where $\theta$ is the coverage, $\mathrm{dCz}$ the height of the carbazole unit $(\approx 0.59 \mathrm{~nm}), \mathrm{d} 2 \mathrm{PACz}$ the height of the full molecule $(\approx 0.9 \mathrm{~nm})$.

Therefore the full expression for the XPS ratio at electron emission angle is $0^{\circ}$ is shown below

$$
\frac{P(2 p)}{\operatorname{In}\left(3 d_{5 / 2}\right)}=3.16 \times \frac{1}{32.16} \times \frac{S F(P)}{S F(I n)}\left\{\frac{\phi e^{\left(-C z(0.59 n m) / \lambda_{P 2 p} \cos (\theta)\right.}}{1-\phi+\phi e^{\left(-2 P A C z(0.9 n m) / \lambda_{I n 3 d 5 / 2} \cos (\theta)\right.}}\right\}
$$

The model $\operatorname{In}\left(3 \mathrm{~d}_{5 / 2}\right) / \mathrm{P}(2 \mathrm{p})$ ratio is depicted graphically as a function of coverage in Figure S2e for the different emission angles used, where the large filled circles are the recorded data points corresponding coverage. Overall a relatively favourable saturated average coverage of $0.92 \theta \pm 0.1 \theta$ is determined, considering the simplifications made in the model. This can be translated into $\approx 4.4 \times 10^{14} 2 \mathrm{PACz}$ molecules per $\mathrm{cm}^{2}$ and compares favourably with the saturated molecular density reported by of Paniagua et al. measured for a phosphonic acid modified ITO surface self-assembled monolayer surface. ${ }^{20}$ 
Table S2 Calculated parameters for the coverage determination.

\begin{tabular}{|c|c|c|c|c|c|}
\hline$\theta$ & Atten.Corr & Corr.P/In atoms & $\begin{array}{c}\text { Overlayer } \\
\text { corr. } \\
1 \mathrm{ML}\end{array}$ & $\begin{array}{c}\text { Predicted } \\
\text { P/In XPS ratio } \\
1 \mathrm{ML}\end{array}$ & $\begin{array}{c}\text { Meas. } \\
\text { P/In } \\
\text { XPS ratio }\end{array}$ \\
\hline 0 & $3 \lambda / 0.951 \lambda$ & $3.16 \times(1 / 32.16)$ & 1.157 & 0.0105 & 0.00776 \\
\hline 33 & $3 \lambda / 0.862 \lambda$ & $3.48 \times(1 / 32.16)$ & 1.191 & 0.0115 & 0.01175 \\
\hline 53 & $3 \lambda / 0.599 \lambda$ & $5.01 \times(1 / 32.16)$ & 1.276 & 0.0177 & 0.01847 \\
\hline 75 & $3 \lambda / 0.262 \lambda$ & $11.45 \times(1 / 32.16)$ & 1.764 & 0.0562 & 0.03234 \\
\hline
\end{tabular}
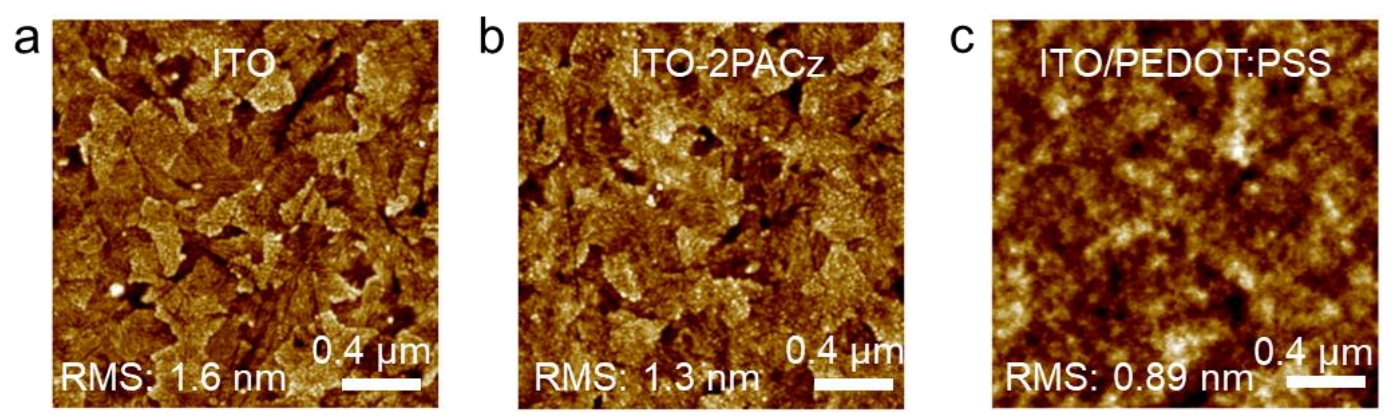

Figure S3. Topography AFM images of (a) ITO, (b) ITO-2PACz, and (c) ITO/PEDOT:PSS (scale bar: $0.4 \mu \mathrm{m}$ ). 

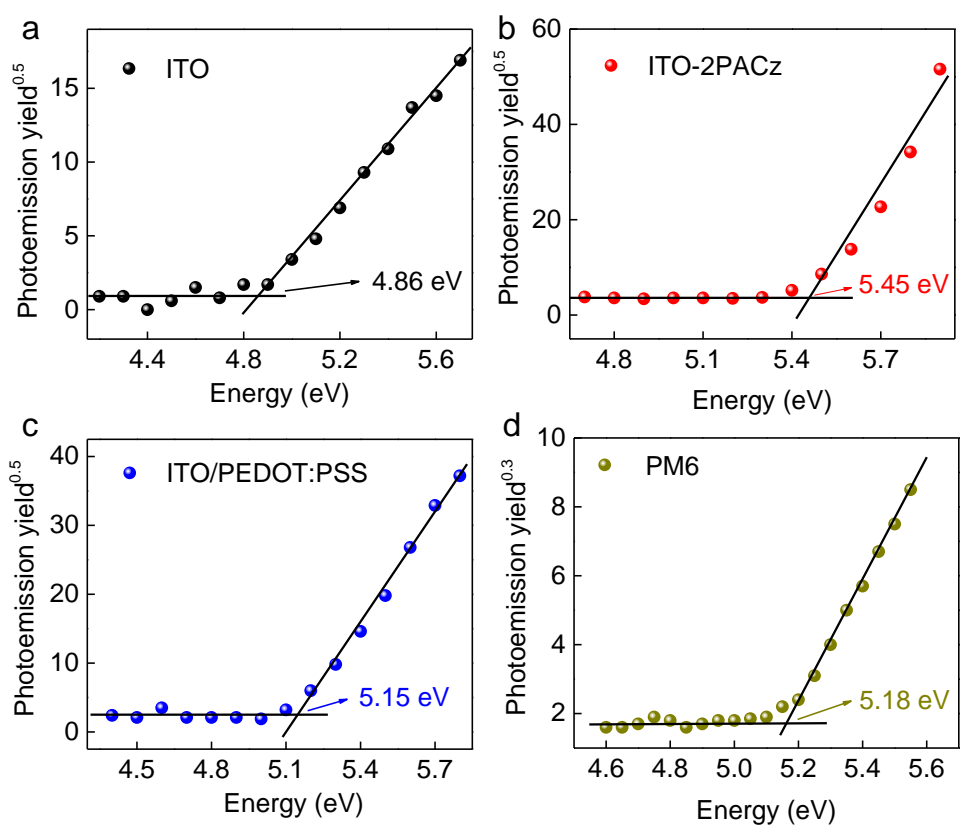

Figure S4. Photoelectron spectroscopy in air (PESA) measurement of (a) ITO, (b) ITO2PACz, (c) ITO/PEDOT:PSS, and (d) PM6 (film on glass) investigated in this study.

Table S3. Work function on various materials films.

\begin{tabular}{|l|c|c|c|}
\hline \multirow{2}{*}{ Solid surface } & \multicolumn{3}{|c|}{ Work function [eV] } \\
\cline { 2 - 4 } & DFT & PESA $^{\mathrm{a}}$ & $\mathrm{KP}^{\mathrm{b}}$ \\
\hline ITO & -4.70 & -4.86 & -4.70 \\
\hline ITO-SAM & -4.90 & -5.45 & -5.71 \\
\hline ITO/PEDOT:PSS & - & -5.15 & -5.19 \\
\hline PM6 & -5.25 & -5.18 & - \\
\hline
\end{tabular}

${ }^{\text {a }}$ Work function was measured from photoelectron spectroscopy in air (PESA).

${ }^{\mathrm{b}}$ Work functions were measured from Kelvin probe (KP).

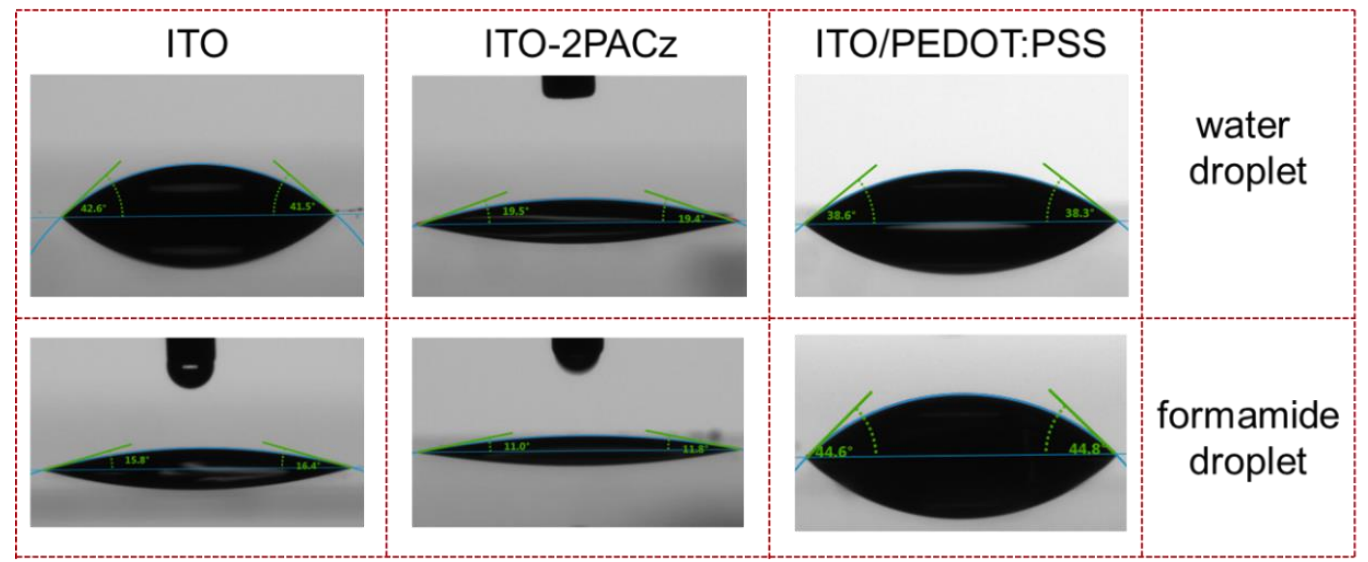


Figure S5. Photographs of water (top row) and formamide (bottom row) droplets in contact with the various surfaces.

Table S4. Contact angles and surface energy on various materials films.

\begin{tabular}{|c|c|c|c|}
\hline Solid surface & $\begin{array}{c}\text { Water } \\
\text { contact angle }^{\mathrm{a}}\end{array}$ & $\begin{array}{c}\text { Formamide } \\
\text { contact angle }\end{array}$ & $\begin{array}{c}\text { Surface energy } \\
{[\mathrm{mN} / \mathrm{m}]^{\mathrm{b}}}\end{array}$ \\
\hline ITO & $41.3 \pm 0.8^{\circ}$ & $16.2 \pm 0.4^{\circ}$ & 57.9 \\
\hline ITO-2PACz & $19.5 \pm 0.3^{\circ}$ & $11.5 \pm 0.5^{\circ}$ & 68.7 \\
\hline ITO/PEDOT:PSS & $38.3 \pm 0.4^{\circ}$ & $44.7 \pm 0.4^{\circ}$ & 59.8 \\
\hline
\end{tabular}

a Average angle calculated from 5 films.

${ }^{\mathrm{b}}$ Surface energy was converted from contact angle values based on Owens method.

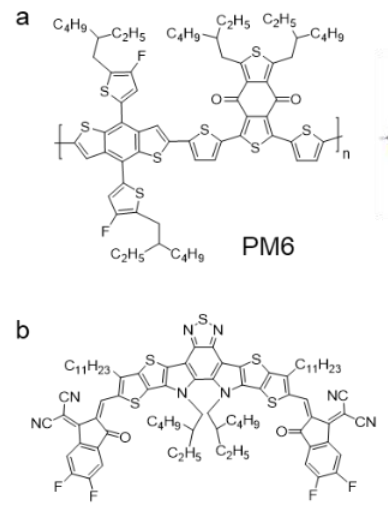

N3
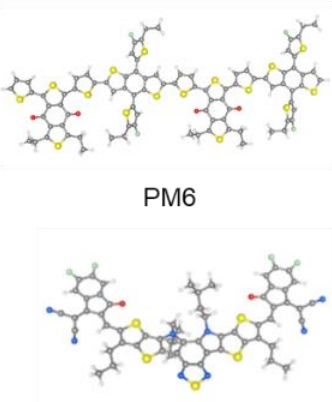

N3

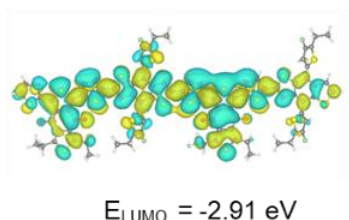

$$
E_{\text {LUMO }}=-2.91 \mathrm{eV}
$$

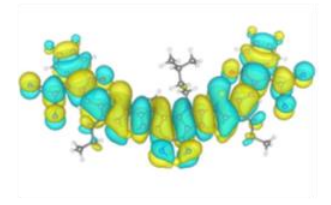

$E_{\text {LUMO }}=-3.86 \mathrm{eV}$
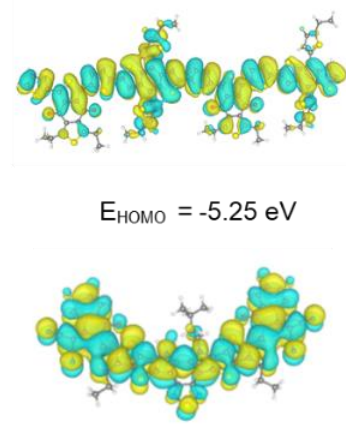

$E_{\text {номо }}=-5.86 \mathrm{eV}$

Figure S6. Molecular structure of (a) PM6 and (b) N3 investigated in this study, and their highest occupied molecular orbitals (HOMO) and lowest unoccupied molecular orbitals (LUMO) calculated via DFT. (C: gray, H: white, S: yellow, O: red, N: blue, F: light green spheres). 

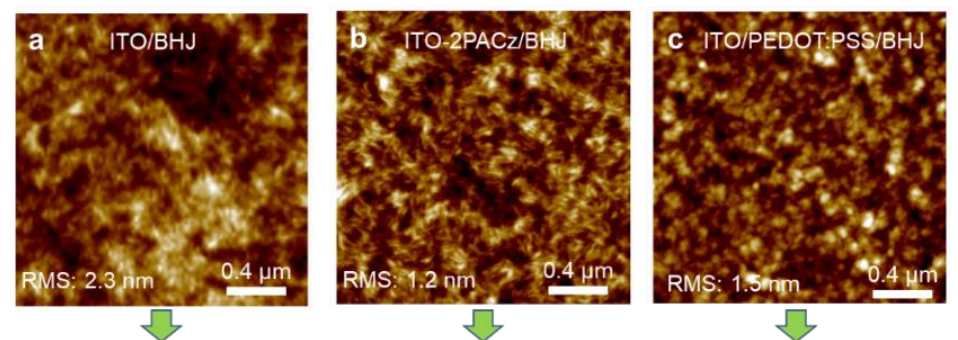

d
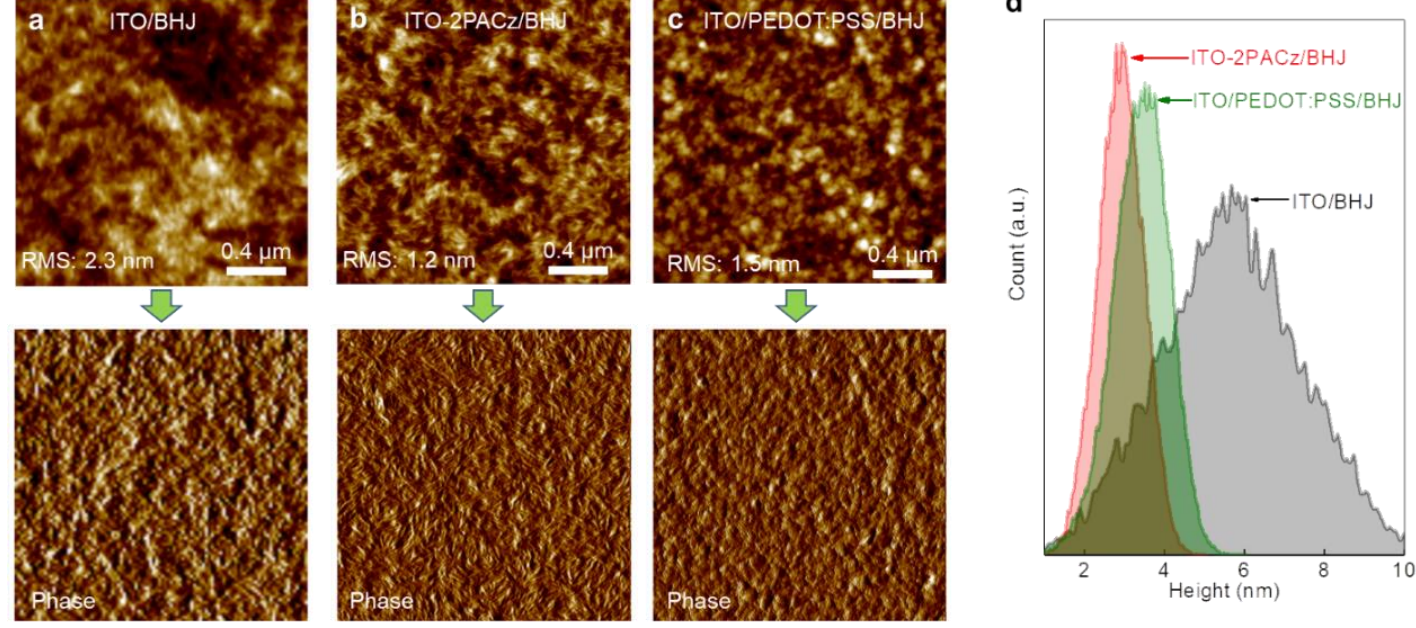

Figure S7. AFM images of PM6:N3 BHJ layers deposited on: (a) bare ITO, (b) ITO2PACz, (c) ITO/PEDOT:PSS, and corresponding phase images (bottom). (d) Surface height histograms extracted from the AFM images in (a-c).

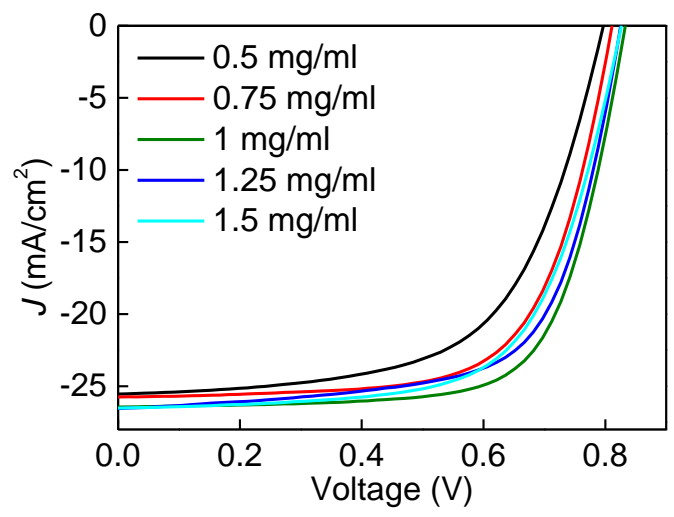

Figure S8. $J-V$ curves of OPV cells based on PM6:N3 where the $2 \mathrm{PACz}$ was spincoated at different concentrations. 


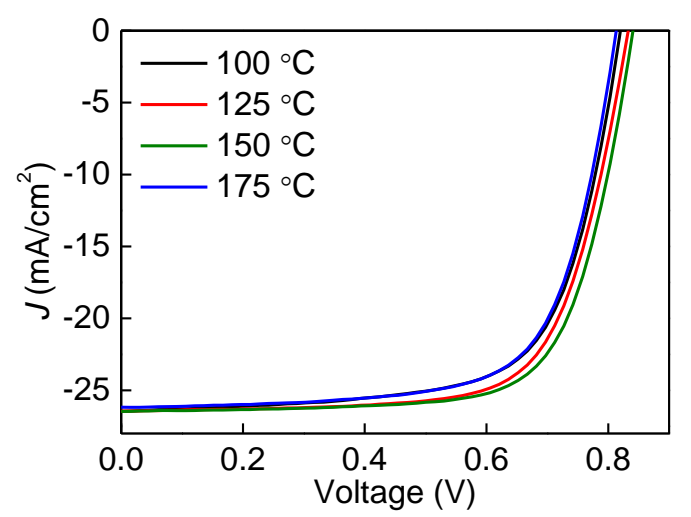

Figure S9. $J-V$ curves of OPV cells based on PM6:N3 where the 2PACz was thermally annealed at different temperatures.

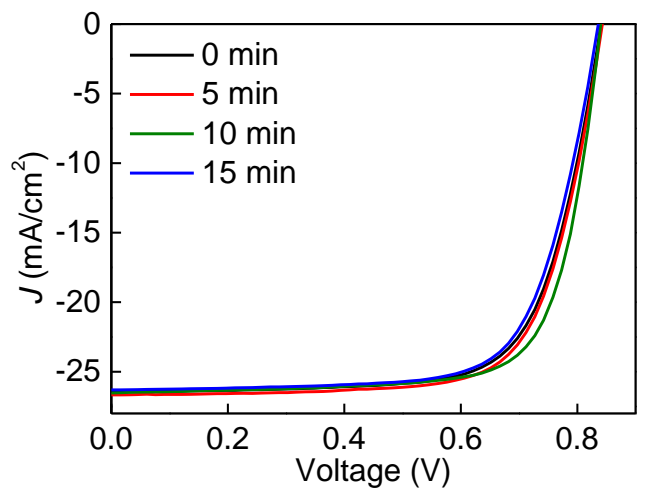

Figure S10. $J-V$ curves of OPV cells based on PM6:N3 where the ITO substrate was treated with plasma at different times.

Table S5. Photovoltaic parameters of devices with different concentrations of $2 \mathrm{PACz}$ in ethanol while the annealing temperature is $125 \mathrm{C}^{\circ}$ under illumination of $\mathrm{AM} 1.5 \mathrm{G}$ $\left(100 \mathrm{~mW} / \mathrm{cm}^{2}\right)$.

\begin{tabular}{ccccc}
\hline Concentration $[\mathrm{mg} / \mathrm{ml}]$ & $V_{\mathrm{OC}}[\mathrm{V}]$ & $J_{\mathrm{SC}}\left[\mathrm{mA} / \mathrm{cm}^{2}\right]$ & $\mathrm{FF}[\%]$ & $\mathrm{PCE}[\%]$ \\
\hline 0.5 & 0.797 & 25.54 & 61.0 & 12.41 \\
0.75 & 0.811 & 25.75 & 67.4 & 14.07 \\
1 & 0.833 & 26.45 & 70.4 & 15.50 \\
1.25 & 0.825 & 26.55 & 67.0 & 14.68 \\
1.5 & 0.826 & 26.52 & 65.5 & 14.35 \\
\hline
\end{tabular}


Table S6. Photovoltaic parameters of devices with different annealing temperatures of $2 \mathrm{PACz}$ while the concentration of $2 \mathrm{PACz}$ is $1 \mathrm{mg} / \mathrm{ml}$ under illumination of $\mathrm{AM} 1.5 \mathrm{G}$ $\left(100 \mathrm{~mW} / \mathrm{cm}^{2}\right)$.

\begin{tabular}{ccccc}
\hline Annealing temperature $\left[\mathrm{C}^{\circ}\right]$ & $V_{\mathrm{OC}}[\mathrm{V}]$ & $J_{\mathrm{SC}}\left[\mathrm{mA} / \mathrm{cm}^{2}\right]$ & $\mathrm{FF}[\%]$ & $\mathrm{PCE}[\%]$ \\
\hline 100 & 0.820 & 26.46 & 68.6 & 14.88 \\
125 & 0.833 & 26.45 & 70.4 & 15.50 \\
150 & 0.841 & 26.47 & 71.6 & 15.93 \\
175 & 0.813 & 26.18 & 69.6 & 14.82 \\
\hline
\end{tabular}

Table S7. Photovoltaic parameters of devices where the ITO substrate was treated with plasma at different times while the annealing temperature is $150 \mathrm{C}^{\circ}$ and the concentration of $2 \mathrm{PACz}$ is $1 \mathrm{mg} / \mathrm{ml}$ under illumination of $\mathrm{AM} 1.5 \mathrm{G}\left(100 \mathrm{~mW} / \mathrm{cm}^{2}\right)$.

\begin{tabular}{ccccc}
\hline Plasma time $[\mathrm{min}]$ & $V_{\mathrm{OC}}[\mathrm{V}]$ & $J_{\mathrm{SC}}\left[\mathrm{mA} / \mathrm{cm}^{2}\right]$ & $\mathrm{FF}[\%]$ & $\mathrm{PCE}[\%]$ \\
\hline 0 & 0.841 & 26.47 & 71.6 & 15.93 \\
5 & 0.843 & 26.67 & 72.1 & 16.21 \\
10 & 0.840 & 26.53 & 74.5 & 16.60 \\
15 & 0.836 & 26.31 & 71.5 & 15.73 \\
\hline
\end{tabular}
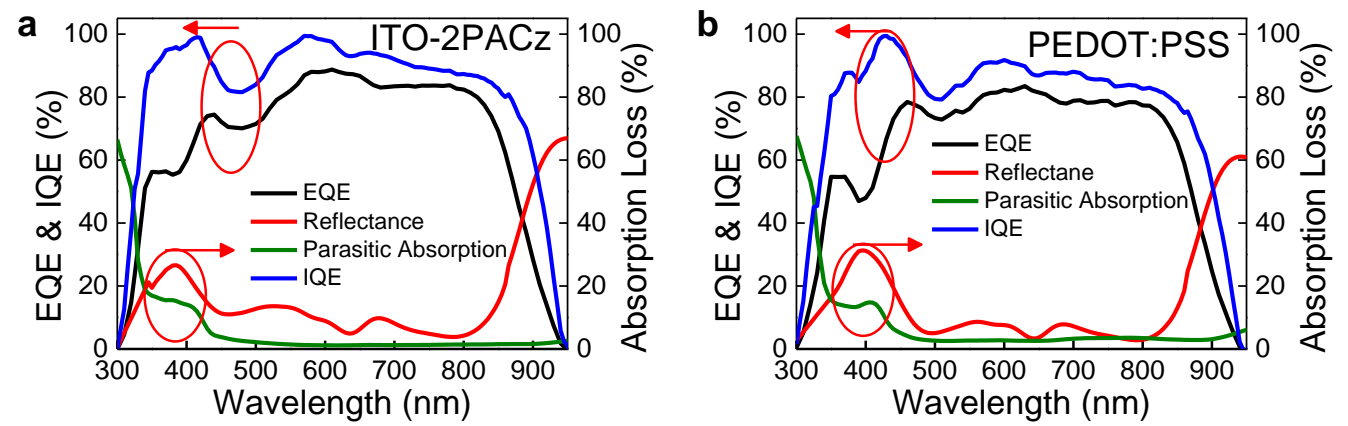

Figure S11. EQE, IQE, reflectance, and parasitic absorption spectra of OPV cells based on PM6:N3 incorporating a) ITO-2PACz and b) PEDOT:PSS. 

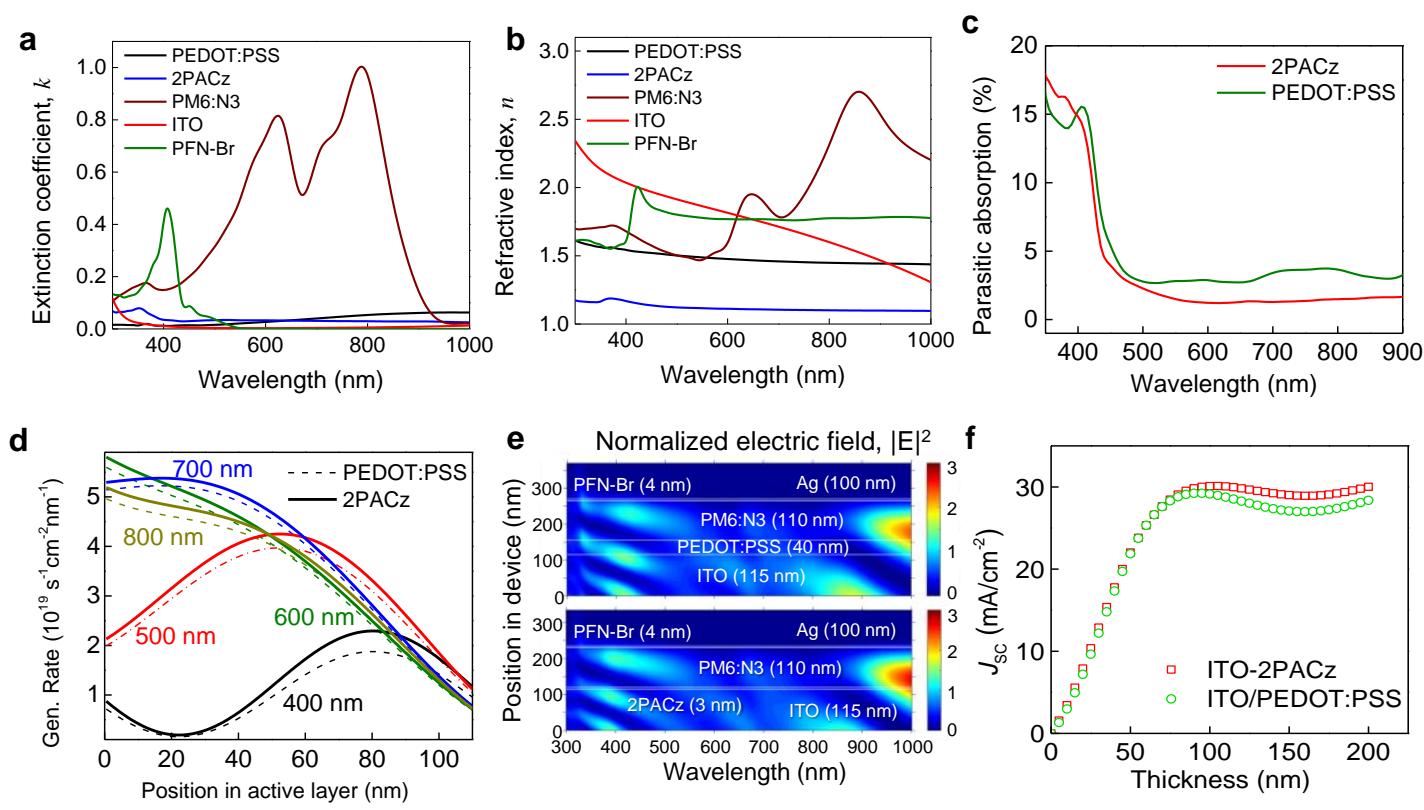

Figure S12. (a) Extinction coefficient and (b) refractive index of layers used in the optical simulation of the OPV device. (c) Simulated parasitic absorption and (d) simulated exciton generation rate profiles in the studied BHJ OPV devices for five different wavelengths (400 nm, $500 \mathrm{~nm}, 600 \mathrm{~nm}, 700 \mathrm{~nm}$, and $800 \mathrm{~nm}$ ). (e) Optical simulations for the optical field intensity $|E|^{2}$ profiles in the studied SAM and PEDOT:PSS-based OPV devices. Device structure used in the transfer-matrix optical simulation: ITO-SAM/PM6:N3/PFN-Br/Ag or ITO/PEDOT:PSS/PM6:N3/PFN-Br/Ag. (f) The $J_{\mathrm{SC}}$ calculated from simulated optical field intensity as a function of $\mathrm{BHJ}$ thickness.
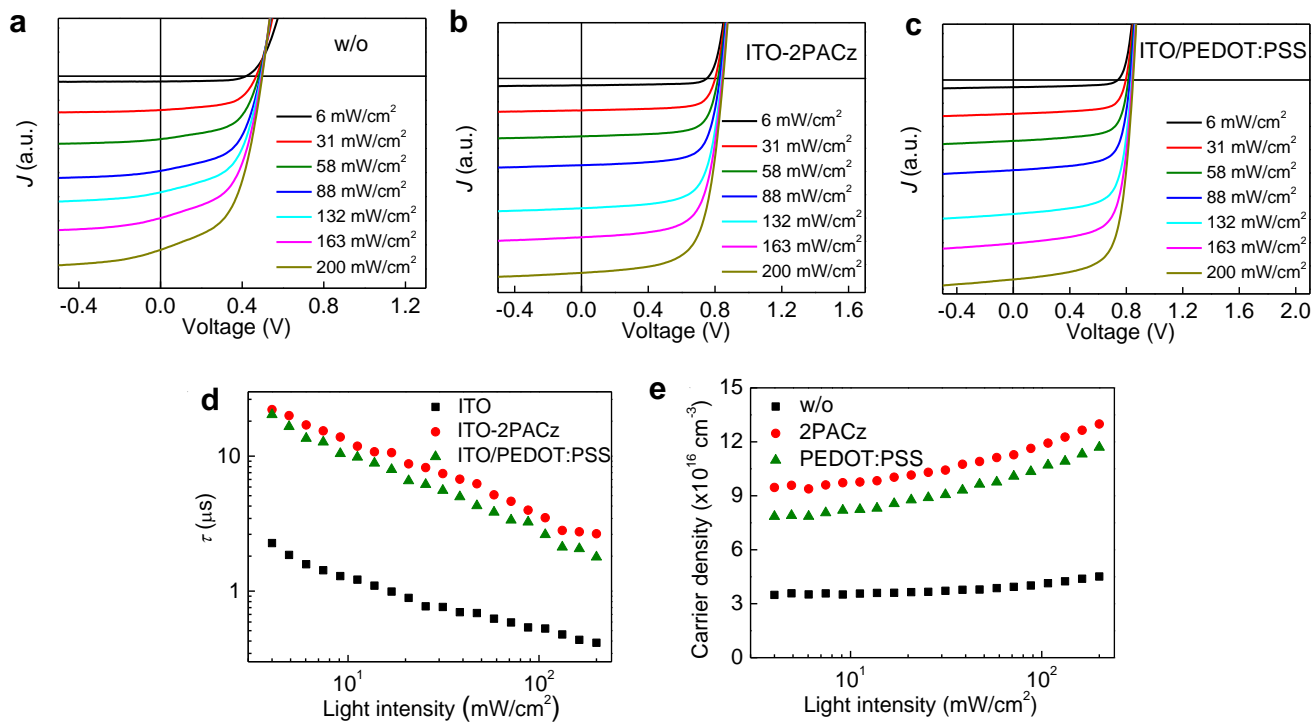

Figure S13. $J-V$ curves vs. light intensity for OPV cells incorporating: (a) ITO, (b) ITO-2PACz, and (c) ITO/PEDOT:PSS. Light intensity dependence of (d) charge carrier lifetime, and (e) carrier density measured for the same cells. 

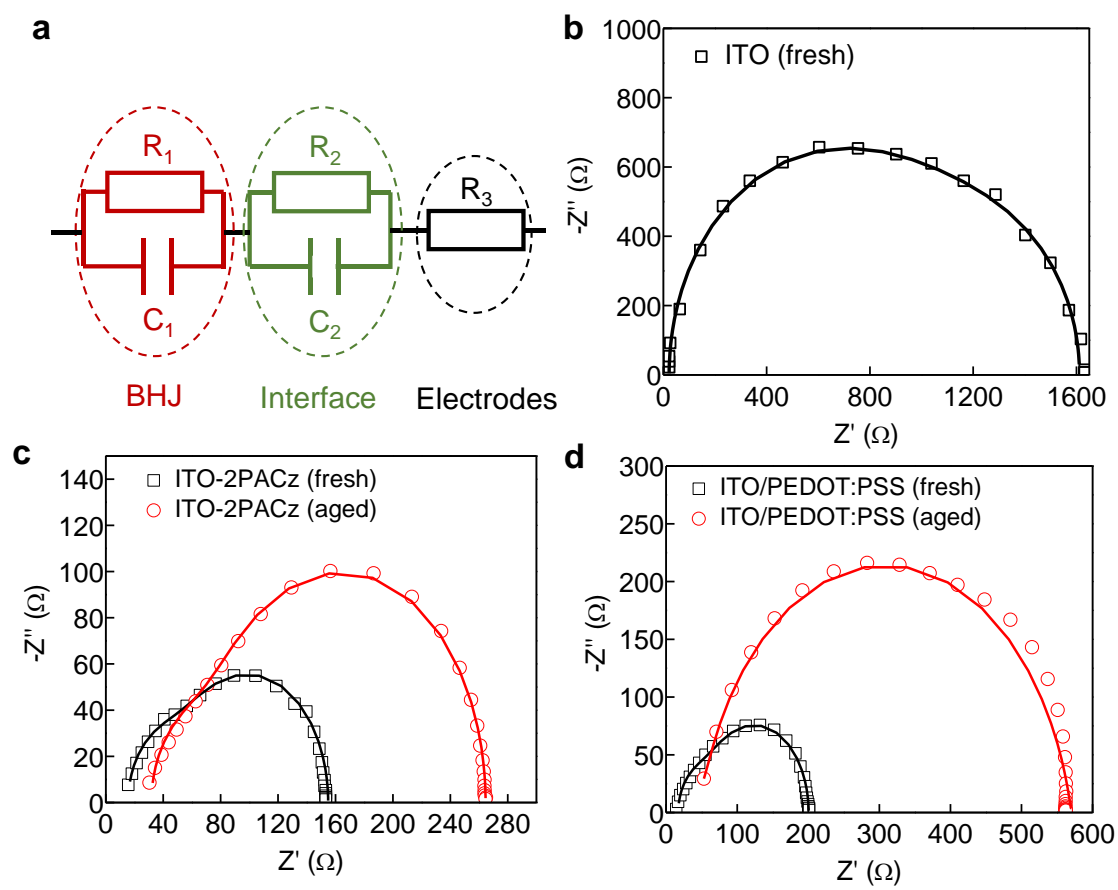

Figure. S14. a) The equivalent-circuit model employed for EIS fitting of the OPVs. Nyquist plots of b) fresh bare ITO, c) fresh and aged $2 \mathrm{PACz}$, and d) fresh and aged PEDOT:PSS-based devices.

Table S8. Summary of the fitting parameter used to describe the Nyquist plots.

\begin{tabular}{cccccccc}
\hline Anode electrode & Type & $R_{1}[\Omega]$ & $C_{1}[\mathrm{nF}]$ & $R_{2}[\Omega]$ & $C_{2}[\mathrm{nF}]$ & $R_{3}[\Omega]$ & $\tau[\mu \mathrm{s}]$ \\
\hline ITO & Fresh & 1049.3 & 0.4 & 540.4 & 3.3 & 22.2 & 0.4 \\
\hline \multirow{2}{*}{ ITO-2PACz } & Fresh & 100.4 & 31.1 & 37.8 & 10.6 & 15.6 & 3.1 \\
& Aged & 190.6 & 13.8 & 42.1 & 8.9 & 31.8 & 2.6 \\
\hline \multirow{2}{*}{ ITO/PEDOT:PSS } & Fresh & 125.3 & 17.1 & 43.5 & 9.5 & 17.4 & 2.1 \\
& Aged & 207.9 & 6.1 & 306.4 & 1.1 & 57.8 & 1.3 \\
\hline
\end{tabular}




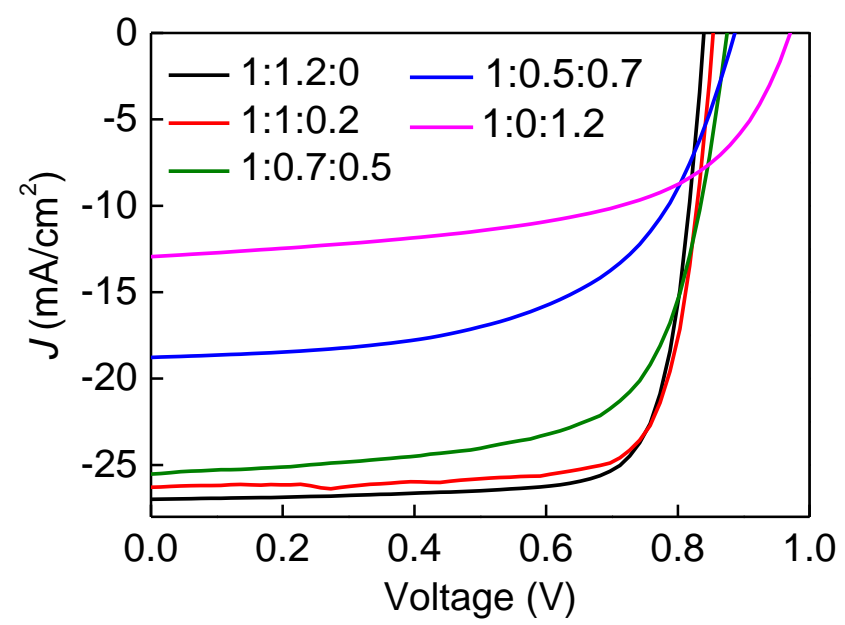

Figure S15. $J-V$ curves of OPV cells with PEDOT:PSS based on PM6:BTP$\mathrm{eC} 9: \mathrm{PC}_{71} \mathrm{BM} \mathrm{BHJ}$ of different compositions (wt $\%$ ).

Table S9. Photovoltaic parameters of OPVs based on PM6:BTP-eC9:PC ${ }_{71} \mathrm{BM}$ with different compositions and PEDOT:PSS as the HTL.

\begin{tabular}{ccccc}
\hline PM6:BTP-eC9:PC ${ }_{71} \mathrm{BM}$ & $V_{\mathrm{OC}}[\mathrm{V}]$ & $J_{\mathrm{SC}}\left[\mathrm{mA} / \mathrm{cm}^{2}\right]$ & $\mathrm{FF}[\%]$ & PCE [\%] \\
\hline $1: 1.2: 0$ & 0.848 & 26.33 & 77.0 & $17.19(16.91 \pm 0.16)$ \\
$1: 1: 0.2$ & 0.854 & 26.28 & 78.2 & $17.52(17.11 \pm 0.19)$ \\
$1: 0.7: 0.5$ & 0.875 & 25.54 & 67.9 & $15.16(14.75 \pm 0.18)$ \\
$1: 0.5: 0.7$ & 0.887 & 18.78 & 58.2 & $9.68(9.25 \pm 0.22)$ \\
$1: 0: 1.2$ & 0.971 & 12.94 & 57.1 & $7.17(6.71 \pm 0.22)$ \\
\hline
\end{tabular}

\section{SI REFERENCES}

(1) Valiev, M.; Bylaska, E. J.; Govind, N.; Kowalski, K.; Straatsma, T. P.; Van Dam, H. J. J.; Wang, D.; Nieplocha, J.; Apra, E.; Windus, T. L.; de Jong, W., NWChem: A comprehensive and scalable open-source solution for large scale molecular simulations. Comput. Phys. Commun. 2010, 181 (9), 1477-1489.

(2) Becke, A. D., Density-functional thermochemistry. III. The role of exact exchange. J. Chem. Phys. 1993, 98 (7), 5648-5652.

(3) Stephens, P. J.; Devlin, F. J.; Chabalowski, C. F.; Frisch, M. J., Ab-Initio Calculation of Vibrational Absorption and Circular-Dichroism Spectra Using Density-Functional Force-Fields. J. Chem. Phys. 1994, 98 (45), 11623-11627.

(4) Godbout, N.; Salahub, D. R.; Andzelm, J.; Wimmer, E., Optimization of Gaussian-type basis sets for local spin density functional calculations. Part I. 
Boron through neon, optimization technique and validation. Can. J. Chem. 1992, 70 (2), 560-571.

(5) Giannozzi, P.; Baroni, S.; Bonini, N.; Calandra, M.; Car, R.; Cavazzoni, C.; Ceresoli, D.; Chiarotti, G. L.; Cococcioni, M.; Dabo, I.; Dal Corso, A.; de Gironcoli, S.; Fabris, S.; Fratesi, G.; Gebauer, R.; Gerstmann, U.; Gougoussis, C.; Kokalj, A.; Lazzeri, M.; Martin-Samos, L.; Marzari, N.; Mauri, F.; Mazzarello, R.; Paolini, S.; Pasquarello, A.; Paulatto, L.; Sbraccia, C.; Scandolo, S.; Sclauzero, G.; Seitsonen, A. P.; Smogunov, A.; Umari, P.; Wentzcovitch, R. M., QUANTUM ESPRESSO: a modular and open-source software project for quantum simulations of materials. J. Phys-Condens. Mat. 2009, 21 (39), 395502.

(6) Blöchl, P. E., Projector augmented-wave method. Phys. Rev. B 1994, 50 (24), 17953.

(7) Perdew, J. P.; Wang, Y., Accurate and simple analytic representation of the electron-gas correlation energy. Phys. Rev. B 1992, 45 (23), 13244-13249.

(8) Momma, K.; Izumi, F., VESTA 3 for three-dimensional visualization of crystal, volumetric and morphology data. J. Appl. Crystallogr. 2011, 44 (6), 1272-1276.

(9) Burkhard, G. F.; Hoke, E. T.; McGehee, M. D., Accounting for Interference, Scattering, and Electrode Absorption to Make Accurate Internal Quantum Efficiency Measurements in Organic and Other Thin Solar Cells. Adv. Mater. 2010, 22 (30), 3293-7.

(10) Kim, J. S.; Park, J. H.; Lee, J. H.; Jo, J.; Kim, D. Y.; Cho, K., Control of the electrode work function and active layer morphology via surface modification of indium tin oxide for high efficiency organic photovoltaics. Appl. Phys. Lett. 2007, 91 (11), 112111.

(11) Das, S.; Joslin, J.; Alford, T. L., Self-assembled monolayer modified ITO in P3HT:PC61BM organic solar cells with improved efficiency. Sol. Energy Mater. Sol. Cells 2014, 124, 98-102.

(12) Li, A. Y.; Nie, R. M.; Deng, X. Y.; Wei, H. X.; Zheng, S. Z.; Li, Y. Q.; Tang, J. $\mathrm{X}$; Wong, K. Y., Highly efficient inverted organic solar cells using amino acid modified indium tin oxide as cathode. Appl. Phys. Lett. 2014, 104 (12), 123303.

(13) Hains, A. W.; Liu, J.; Martinson, A. B. F.; Irwin, M. D.; Marks, T. J., Anode Interfacial Tuning via Electron-Blocking/Hole-Transport Layers and Indium Tin Oxide Surface Treatment in Bulk-Heterojunction Organic Photovoltaic Cells. Adv. Funct. Mater. 2010, 20 (4), 595-606.

(14) Zhang, S. H.; Zhan, L. L.; Li, S. X.; Li, C. Z.; Chen, H. Z., Enhanced performance of inverted non-fullerene organic solar cells through modifying zinc oxide surface with self-assembled monolayers. Org. Electron. 2018, 63, 143-148.

(15) Xu, X.; Xiao, J.; Zhang, G.; Wei, L.; Jiao, X.; Yip, H.-L.; Cao, Y., Interfaceenhanced organic solar cells with extrapolated T80 lifetimes of over 20 years. Sci. Bull. 2020, 65 (3), 208-216.

(16) Yip, H. L.; Hau, S. K.; Baek, N. S.; Jen, A. K. Y., Self-assembled monolayer modified $\mathrm{ZnO} /$ metal bilayer cathodes for polymer/fullerene bulk-heterojunction solar cells. Appl. Phys. Lett. 2008, 92 (19), 193313. 
(17) Yip, H. L.; Hau, S. K.; Baek, N. S.; Ma, H.; Jen, A. K. Y., Polymer solar cells that use self-assembled-monolayer-modified $\mathrm{ZnO} /$ Metals as cathodes. Adv. Mater. 2008, 20 (12), 2376-2382.

(18) Wong, W. W. H.; Rudd, S.; Ostrikov, K.; Ramiasa-MacGregor, M.; Subbiah, J.; Vasilev, K., Plasma deposition of organic polymer films for solar cell applications. Org. Electron. 2016, 32, 78-82.

(19) Stubhan, T.; Salinas, M.; Ebel, A.; Krebs, F. C.; Hirsch, A.; Halik, M.; Brabec, C. J., Increasing the Fill Factor of Inverted P3HT:PCBM Solar Cells Through Surface Modification of Al-Doped $\mathrm{ZnO}$ via Phosphonic Acid-Anchored C60 SAMs. Adv. Energy Mater. 2012, 2 (5), 532-535.

(20) Paniagua, S. A.; Li, E.; Marder, S. R., Adsorption studies of a phosphonic acid on ITO: film coverage, purity, and induced electronic structure changes. Phys. Chem. Chem. Phys. 2014, 16 (7), 2874-2881.

(21) Seah, M., Simple universal curve for the energy - dependent electron attenuation length for all materials. Surf. Interface Anal. 2012, 44 (10), 1353-1359.

(22) Paramonov, P. B.; Paniagua, S. A.; Hotchkiss, P. J.; Jones, S. C.; Armstrong, N. R.; Marder, S. R.; Brédas, J.-L., Theoretical characterization of the indium tin oxide surface and of its binding sites for adsorption of phosphonic acid monolayers. Chem. Mater. 2008, 20 (16), 5131-5133.

(23) Hanson, E. L.; Schwartz, J.; Nickel, B.; Koch, N.; Danisman, M. F., Bonding SelfAssembled, Compact Organophosphonate Monolayers to the Native Oxide Surface of Silicon. J. Am. Chem. Soc. 2003, 125 (51), 16074-16080. 